\title{
EDUCOMUNICAÇÃO: \\ CONTEXTUALIZANDO O \\ PROCESSO DE ATRIBUIÇÃO DE SENTIDOS E SIGNIFICADOS NO DELINEAMENTO DO CONCEITO
}

José Vicente Freitas ${ }^{1}$

Resumo: Discorre sobre o contexto e as experiências que levaram a formulação do conceito de educomunicação, buscando identificar como, gradualmente, foram sendo atribuídos sentidos e significados a esta categoria. Neste contexto, destaca as experiências e concepções desenvolvidas pelo comunicador-educador Mario Kaplún, criador, entre outros, do método casetteforo. Destaca a influência do pensamento freiriano na consolidação do conceito. Ressalta algumas das experiências educomunicativas levadas à cabo na América Latina e identifica perspectivas e possibilidades na aplicabilidade do conceito.

Palavras-chave: Educomunicação Socioambiental; Educação Ambiental; Mario Kaplún; América Latina; Experiências Educomunicativas.

\footnotetext{
${ }^{1}$ Professor da Universidade Federal do Rio Grande - FURG - Instituto de Ciências e Informação (ICHI) e
} do Programa de Pós-Graduação em Educação Ambiental (PPGEA). E-mail: jvfreitas45@gmail.com. 


\section{Considerações Iniciais}

Via de regra, ao longo da ainda recente história da educação ambiental, os processos de comunicação e informação sempre foram considerados como estratégicos na ampliação da escala e alcance na formação de educadores e educadoras ambientais, e igualmente no esforço de desenvolvimento de novos valores, atitudes, habilidades e comportamentos necessários na construção de uma sociedade sustentável. As experiências de comunicação desenvolvidas tanto no âmbito das organizações não governamentais quanto no contexto dos governos ganharam fôlego quando, entre os educadores ambientais, 0 conceito de educomunicação socioambiental ganha espaço, sugerindo novas perspectivas e possibilidades, inspiradas no envolvimento e participação efetiva dos atores sociais na apropriação dos meios técnicos e na elaboração das suas próprias peças de comunicação. A partir deste momento, a educomunicação torna-se referência no fazer do educador ambiental.

Não obstante, o conceito de educomunicação socioambiental hoje amplamente acolhido pelo campo da EA, é herdeiro de uma história e de um conjunto de experiências que, censo comum, encontra referência na trajetória de Mário Kaplún e suas formulações. E é um pouco deste resgate o principal objetivo deste artigo, fruto de uma síntese do que já foi produzido sobre o assunto.

\section{Histórias, experiências e encontros na emergência do conceito}

Educação e Comunicação são duas áreas que possuem vários pontos convergentes, pois ambas são essenciais para que ocorram transformações e mudanças sociais de fato. Esses dois campos associados possibilitam a democratização da informação, da cultura e do conhecimento, contribuindo assim para uma construção social baseada na cidadania. "A convergência das duas áreas, educação e comunicação, criando um novo campo do saber, a Educomunicação, busca um objetivo comum que é a construção da cidadania" (FREIRE; CARVALHO, 2012 p.1).

Podemos dizer que a utilização da comunicação como ferramenta pedagógica no processo ensino-aprendizagem não é uma prática recente, pois em meados da década de 1960, Paulo Freire já anunciava que a educação estaria cada dia mais interligada à comunicação. Segundo Citelli (2004), a inter-relação educação/comunicação também foi a propulsora da expansão do mundo midiático no século $X X$, e foi através da imprensa escrita, do rádio e da televisão que se remodelaram os conceitos de ensino-aprendizagem, conhecimento e educação. Neste sentido, Schaum (2004, p.22) afirma que:

[...] a inter-relação comunicação e educação cadeias semióticas que se apresentam transversalmente como imagens e formas de atuar com e para comunicação no contexto da educação e da cultura, que podemos denominar fluxos informacionais que vão ecoar diante das singularidades dos grupos, comunidades e indivíduos propiciando 0 surgimento das articulações comunicativas peculiares. 
Assim, estabelece-se a interação comunicativa entre indivíduos e grupos no compartilhamento mútuo de saberes e significados em torno de suas práticas sociais.

Em 1996 surge o Núcleo de Comunicação e Educação da Universidade de São Paulo (NCE), que se dedica a estudar a inter-relação Educação/Comunicação. O professor Ismar de Oliveira Soares, coordenador do NCE, em entrevista ao Jornal Folha Dirigida, na edição de № 1.396 (08 a 14/12/2005), atribui a autoria do conceito "Educomunicação" a Mario Kaplún. Este conceito é inicialmente usado por ele como sinônimo de "educação para los médios", ou conceito de comunicação educativa.

Mario Kaplún, argentino de nascimento e uruguaio por opção, nasceu em 1926 em Buenos Aires, na Argentina. Segundo Caracristi (200, p.34), Kaplún cursou magistério mas nunca chegou a exercer a profissão de professor do ensino básico, iniciou curso superior de Filosofia e Psicologia, e um pouco antes de graduar-se descobriu outra maneira, segundo ele mesmo, de fazer educação através dos meios de comunicação. Esta descoberta fez com ele abandonasse o curso superior. Caracristi baseia-se em depoimento do próprio Kaplún, em uma biografia escrita por José Marques de Melo, no início dos anos 40. Neste trabalho biográfico, encontramos a informação de que o autor teria abandonado o curso superior que frequentava até então, mesmo porque nesta época não existiam cursos universitários especificamente de comunicação em Buenos Aires, e nem mesmo no contexto continental da América Latina. Por isso, segundo o próprio Kaplún - "nós, os comunicadores, nos formávamos na práxis"2, afirmação que denota o caráter genuinamente comunitário, libertador e contra-hegemônico que demarcam o bojo da gestação das experiências educomunicativas.

Foi aos 19 anos de idade, em 1942, que Mario Kaplún põe no ar seu primeiro programa de rádio educativa pela Rádio Del Estado (emissora oficial) e a Red Splendid (cadeia privada de cobertura nacional) na Argentina. A programação educativa foi transmitida durante três anos até que o governo militar da Argentina cancelou o programa. Em 1951, sob o populismo argentino, Kaplún era o único jornalista radical e independente que o governo tolerava e, segundo Caracristi, o autor não cedeu à direção da imprensa e propaganda do peronismo e desta forma vai para o Uruguai. Ele teria dito, na oportunidade: "Encurralado, optei por emigrar em busca de ares mais livres e mais dignos".

No Uruguai, Kaplún com sua família, mulher e filhos, continuou a escrever e dirigir programas de rádio, mas a remuneração que obtinha não era suficiente para manter sua família; sendo assim se viu obrigado pelas circunstancias a optar pela publicidade. E foi justamente este momento que propiciou ao comunicador um conhecimento mais detalhado deste meio com suas técnicas, modos de produção e da lógica comercial das agências, que posteriormente se refletem em sua metodologia de trabalho. Em 1962 Kaplún iniciou sua experiência na televisão no

\footnotetext{
${ }^{2}$ Tradução livre da autora, do espanhol para o português.

${ }^{3}$ Idem.
} 
Uruguai, produzindo e apresentando um programa de opinião em um formato de debates políticos, sociais bastante polêmicos.

Em 1968, o Uruguai passava por um período de transformações políticas e sociais; o então presidente Pacheco Areco, instaura medidas de censura na imprensa. E mais uma vez devido a circunstâncias políticas, Kaplún se vê obrigado a procurar novos caminhos e sai da televisão e volta para o rádio, lugar onde desenvolveu a maior parte da metodologia e da técnica da Educação Comunicacional.

Dentre as várias iniciativas produzidas pelo autor, o programa Jurado 13 foi o que lhe trouxe reconhecimento, tendo sido produzidas cinco séries num total de duzentos programas para o Serviço Radiofônico para América Latina (SERPAL), até culminar no seu exílio na Venezuela, o que o levou a trilhar outros caminhos. Com a proposta do programa "Jurado 13", Kaplún recebeu o primeiro prêmio com a proposta de rádio educativa para setores populares, promovido pela Fundação Europeia Humanum que organizou o concurso latino-americano de programas de rádio. Foi através do programa Jurado 13 que propiciou ao autor conhecer com maiores detalhes os problemas cruciais que afetavam naquele momento a América Latina; a programação foi realizada em série durante dois anos. Segundo Kaplún (1978) - "Para escrevê-la, fiz, junto a minha companheira Ana, uma inesquecível viagem de documentação que compreendeu sete países da América Latina. Toquei a fundo a realidade de nossa América Pobre" ${ }^{\text {. }}$.

É neste sentido que Caracristi (2000, p.28) aponta o programa Jurado 13 como grande propulsor do método de educação e comunicação proposto por Kaplún, além de ter sido o que mais reconhecimento the proporcionou. Foi traduzido em muitas línguas, inclusive no Aymara $^{5}$ e the concedeu o prêmio Mundial "UNDA-Sevilla" e com este o "Tulipán de Plata" no certame "Kom Over de Brug", na Holanda, para produções do Terceiro Mundo.

Segundo Caracristi:

Apesar da nacionalidade Argentina, foi no Uruguai que Kaplún iniciou sua metodologia de educação e comunicação, depois do exílio na Venezuela em meados de 1978. Para seus amigos, Kaplún tem uma trajetória "polifacética". Em síntese, o comunicador-educador é um faz de tudo. Ao longo dos seus 56 anos de profissão, Kaplún pode ser considerado um teórico que preconiza a "praxis". Foi comunicador prático (rádio, televisão, meios grupais), publicitário, docente, investigador, autor de obras de comunicação, "y unas cuantas cosas más".(2000, p. 35)

${ }^{4}$ Tradução livre da autora.

${ }^{5}$ Aymará é a língua falada pelo povo Aymara dos Andes, sendo apenas uma dos várias línguas nativas americanas com mais de três milhões de falantes. Aymara, junto com Quechua e espanhol, é uma língua oficial da Bolívia.

Revbea, São Paulo, V.10, N²: 149-162, 2015. 
Desse modo, notamos que Kaplún trouxe contribuições de diversos ramos do conhecimento humano como parte integrante da estruturação da proposta educomunicativa, provavelmente sintetizando as diferentes contribuições do saber científico e práxico na composição do seu viés educomunicativo.

Neste sentido, em sua caminhada e dando continuidade à sua metodologia de educação, Kaplún foi convidado pelo governo de Quito a desenvolver um trabalho de oficinas de rádio para alunos do curso superior. Foi destaque deste trabalho, a oficina de Produção de Radiodramas para jovens escritores de rádio de toda a América Latina, realizada entre 1983-1984. E foi através desta experiência que o autor teve a oportunidade de inovar, em termos metodológicos, o que foi registrado posteriormente no livro publicado pelo CIESPAL e pela Rádio Nederland Trainning Centre (RNTC): Um taller de radiodramas: su metodologia, su processo (Quito: 1985). Muitos comunicadores populares foram formados em oficinas, seminários, encontros dos movimentos populares e não nas graduações universitárias pela América Latina. Na metodologia empregada nesta experiência, Kaplún foi buscar inspiração em Paulo Freire, o uso da comunicação enquanto processo comum a todos, como diálogo, capacidade de expressão e direito à comunicação.

De certo modo, pode-se dizer que é um modelo gestado na América Latina. Mas, recebeu valiosas contribuições de pedagogos e sociólogos europeus e norte-americanos, na nossa região Freire e outros educadores imprimiram com clareza a orientação social, política e cultural e a elaboraram como uma 'pedagogia do oprimido' como uma educação para a democracia e um instrumento para a transformação da sociedade (KAPLÚN, 1998, p.45).

Aqui, compreendemos o caráter ideológico da faceta pedagógica que compôs a prática educomunicativa desde o seu nascedouro, revelador de uma orientação de crítica social às desigualdades e às formas de opressão no sentido da mudança social.

Dentre os vários trabalhos desenvolvidos por Mário Kaplún, também podemos destacar outros, que foram igualmente de grande importância e contribuição para a Comunicação e para Educação: o método de leitura crítica e o método do Cassette-Foro.

O método Cassette-Foro desenvolvido por Mário Kaplún, tinha como objetivo o uso da comunicação, bem como dos meios, para a organização popular, ou seja, grupos organizados, comunidade de bairro, associações, sindicatos, e outros ligados à classe trabalhadora. $O$ objetivo do projeto principal não era apenas produzir programas para serem veiculados na programação da rádio comercial, mas sim contribuir para que o povo da América Latina tivesse voz e vez. 
(...) Kaplún enfatiza o papel do rádio no contexto de uma América Latina de alfabetos e analfabetos, pobres e ricos, populações urbanas e rurais mas, principalmente, enfoca o rádio como propulsor e difusor da educação à população que não tem acesso a outros meios (2000, p. 36).

Todavia, Mario Kaplún não foi o único autor a refletir sobre a influência dos meios de comunicação, no caso, o rádio, sobre a população através de sua programação alienadora. Dentre vários autores cabe destacar que Juan Diaz Bordenave, na América Latina, em seus estudos, já havia conjecturado sobre esta tendência do rádio. Mas Kaplún vai além de apenas identificar o problema e aponta para um resultado, uma solução para esta questão, e usou como resposta para a programação alienadora presente nas rádios a produção de programas de boa qualidade, não só em termos técnicos, mas principalmente programas que focavam os reais interesses sociais, bem como local e regional.

Em uma de suas obras, Producción del programas de rádio. El guión, la realización" (1978), M. Kaplún traz a proposta pedagógica que procura ir além do domínio das técnicas radiofônicas, pois se preocupa em propor um ponto de vista ideológico, no que diz respeito à situação de dominação e de isolamento das classes populares da América Latina. Realmente ele se mostrava preocupado em propor algo mais que uma teoria, mas estudar e apontar soluções viáveis para 0 cenário de uma América Latina de iletrados. E naquele momento o rádio é para Kaplún uma ferramenta útil e de grande alcance das massas, capaz de promover uma comunicação coletiva e com uma função social a cumprir frente as necessidades das massas populares.

Segundo Caracristi, nesta obra, na perspectiva de promover educação através do rádio, Kaplún se apoia na teoria de Bordonave, que aponta três formas de opções educativas: i) educação que põe ênfase nos conteúdos; ii) educação que põe ênfase nos resultados; iii) educação que põe ênfase no processo.

A Educação que põe ênfase nos conteúdos corresponde àquela educação tradicional, que se baseia na transmissão de conhecimentos e valores de uma geração para outra. Geralmente é autoritária, onde o professore é o ser instruído e dotado de todo conhecimento, que se encarrega de ensinar, depositar conhecimento na mente do aluno. Neste tipo de educação o aluno é apenas o receptor de informações. Segundo o autor, este tipo de educação foi reconhecido por um dos mais críticos educadores brasileiros, Paulo Freire, que a denomina como Educação Bancária.

A Educação que põe ênfase nos resultados é a que mais tem influenciado a comunicação e, segundo Kaplún, requer uma abordagem mais ampla já que é a mais utilizada como textos de estudos nos países latinos e que este modelo surgiu como primeira resposta ao problema de subdesenvolvimento. Como a solução apontada para a pobreza da América Latina era a "modernização", ou seja, seria necessário adotar os mesmos métodos de produção dos países desenvolvidos. Era de suma importância acelerar a produção de bens e assim aumentar a produtividade, mas para se chegar até este ponto era 
primordial a introdução de novas tecnologias. Sendo assim, a educação deveria servir para alcançar estas metas. Segundo Kaplún (1978) "Los medios de comunicación debían ser utilizados para instrumentar este cambio y cumplir esta función permanente y penetrante de persuasión. De ahí la importancia que este modelo de desarrollo asignó a las técnicas de comunicación"

Neste contexto, a comunicação passa a exercer uma função muito maior, pois segundo Kaplún, passa a ser uma arte de provocar significados e produzir comportamentos, promover trocas no pensamento, até mesmo no sentimento e na ação das pessoas, através da produção e a emissão das mensagens.

A Educação que põe ênfase no processo destaca a importância do processo de transformação das pessoas e das comunidades. As preocupações com conteúdos a serem comunicados e os efeitos em termos de comportamento da comunicação ficam em segundo plano, não são priorizados. Mas o que realmente importa e é priorizado neste método é a interação dialética entre as pessoas e suas realidades, bem como o desenvolvimento de suas capacidades intelectuais de consciência social. Daí o seu nome, "processual".

Em síntese, podemos dizer que para o autor o primeiro tipo de educação propõe que o sujeito aprenda, o segundo que o sujeito faça e o terceiro que o sujeito pense.

Portanto, o terceiro modelo, endógeno, ressalta o "processo". E este terceiro modelo é fundamental para que se possa compreender a Educomunicação, pois é basicamente referenciado em Paulo Freire (denominado de educação libertadora ou transformadora: ação-reflexão-ação).

Baseado no livro Pedagogia do Oprimido, de Paulo Freire (2001), o terceiro modelo tem como pressuposto central a educação para a cidadania, para a democracia como ferramenta para a transformação da sociedade. Suas bases são a práxis, "reflexão e ação do homem sobre o mundo para transformá-lo". Fica muito claro que o objetivo desta concepção é de formação e transformação. Educacionalmente a concepção é a seguinte: um educador - educando com um educando - educador. Acredita-se que ninguém se educa sozinho; os homens se educam entre si mediados pelo mundo. "Essa trajetória na qual os homens se educam entre si é precisamente o processo educativo" (KAPLÚN, 2002, p. 45).

A ênfase no processo significa ver a educação como um processo permanente, em que o sujeito vai descobrindo, elaborando, reinventando, fazendo do conhecimento algo seu. Um processo de ação-reflexão-ação que o educando produz a partir de sua realidade, a partir da sua experiência, desde sua prática social, juntamente com todos os outros que participam desse processo. O papel do educador, na educação processual, é de acompanhar o educando, estimular o processo de análise e reflexão para facilitar, mas também para aprender e construir junto. A estratégia é a problematização, que deve auxiliar a pessoa a desmistificar sua realidade, tanto física como social.

Ainda nessa perspectiva, a educação nunca é individual, mas sempre grupal. "Ninguém se educa sozinho", mas através de experiências compartilhadas, na integração com os outros. Para este tipo de educação podemos fazer uso de 
vários tipos de recursos audiovisuais ou outros recursos tecnológicos. A intenção final é a de problematizar e assim estimular discussões, diálogos, reflexões e a participação dos envolvidos.

Baseado nestas ideias, Kaplún vai dizer que todo ser humano é dotado e tem faculdades para emitir e receber informações, e que da mesma forma tem o direito de participar do processo de comunicação, podendo atuar tanto como receptor quanto como emissor. Sendo assim, um comunicador popular também deve conhecer a linguagem dos meios para poder usá-los dando, pois, vez e voz aos educandos.

Em seu livro "Comunicación entre grupos: el método del cassette-foro" (1984), Mario Kaplún relata sua experiência com este sistema de comunicação, concebido para promover educação entre adultos de organizações populares rurais e urbanas e núcleos cooperados. O método Cassette-foro foi aplicado em diferentes países latinos, na tentativa de acabar com o analfabetismo através do uso de novas tecnologias (na época utilizou fitas cassetes); Kaplún buscou inspiração em uma experiência realizada pelo francês Célestin Freinet, que aconteceu no sul da França durante a década de 20. No caso de Freinet, um educador de classes pobres dos Alpes em Bar-sur-Loup, encontrou como solução para o problema da falta de retorno dos alunos e da apatia das classes que foi solucionada através do uso de uma mini imprensa manual (mini jornal). Na verdade esta experiência promove o uso da imprensa, um meio de comunicação, em sala de aula como uma forma de estimular a produção educativa através da participação e interação entre os educandos, pois despertava interesse e entusiasmo. Esta experiência foi tão exitosa que logo outras localidades da França também adotaram o método proposto por Freinet, e como resultado possibilitou aos filhos de camponeses e operários, tradicionalmente inseridos no sistema de escola de segunda classe, superar o clássico sistema cultural e desenvolver a sua própria consciência social. A concepção pedagógica de Freinet serviu de estímulo para Kaplún e uma vez que no conceito de educação comunicativa, as experiências estão sempre se inovando, o autor passou a experimentar trabalhos usando vídeo.

Do que conseguimos apresentar e resenhar até esta altura já nos permite inferir, principalmente pela incursão na trajetória político-social de Mario Kaplún como parte integrante do surgimento do conceito de "comunicação para as mídias" ou educomunicação educativa, a natureza do conceito de educomunicação e o caráter contra-hegemônico e popular das práticas educomunicativas. Nesse contexto, é possível compreender a educomunicação como estratégia de resistência a práticas autoritárias de exercício do poder, assim como meio de combate ao monopólio dos meios de comunicação nas mãos de poucos.

Neste ponto é possível marcar o entendimento da educomunicação como ferramenta de ação e protesto das classes oprimidas da sociedade às formas de dominação sociais, políticas e econômicas. A tecnologia da comunicação passa a constituir-se como ferramenta para a emancipação dos seres humanos no processo em que a educomunicação desponta como novo campo do saber em favor da construção da cidadania. 


\section{América Latina: palco da difusão da práxis educomunicativa}

As teorias, conceitos e experiências de Kaplún foram disseminadas pela América Latina. Muitas oficinas formaram comunicadores populares como também o uso do Cassette-Foro ganhou e alcançou muitos espaços. Com base no trabalho de Caricristi (2000), sobre "As Ideias de Mario Kaplún", foi possível elaborar um quadro com a síntese de como ocorreram algumas experiências pela América Latina inspiradas nas suas concepções.

\section{Vejamos:}

1 - Enquanto escrevia o livro La educación por la comunicación, publicado em 1992, Kaplún acompanhava as novidades do vídeo e das suas possibilidades como ferramenta que poderia potencializar a educação a distância bem como a comunicação educativa. Mas o autor reconhece que em muitos casos as inversões entre potencialidades do meio e seu uso efetivo, pode ser frustrante. Declarações como de Luiz Santoro, na ocasião, presidente da Associação Brasileira de Vídeo no Movimento Popular, Kaplún mostra que o Brasil foi uma das nações da América Latina que mais subutilizou o equipamento. Darcy Ribeiro, também reconheceu o fenômeno, do uso indiscriminado do vídeo no Brasil. De qualquer forma, Kaplún aponta algumas experiências completas desenvolvidas na América Latina.

2 - Em Lima, a "Asociación de Comunicadores Sociales - "Calandria", um centro cujo trabalho é o de acompanhar e apoiar organizações populares, produziu vídeos informativos chamado "Como nosotros", que pela boa qualidade comunitária do material produzido e pela execução de uma rede social de distribuição, assegurou a efetiva circulação e uso dos mesmos. Este vídeo mostra como os comunicadores de Calandria promoveram um projeto de vídeo a serviço das organizações populares femininas, identificando três núcleos de problemas: o comunicativo, o educativo e o político.

3 - Na Venezuela um programa chamado Foruco contemplou 16 Centros de Educação Popular afiliados a União Venezuelana de Centros de Educação Popular (UVECEP) e localizados geograficamente em oito estados do país; o trabalho foi também assessorado pelo Centro de Serviço de Ação Popular (CESAP). Este programa tinha como objetivo abordar temas que solicitassem, de forma eficaz, a participação popular da comunidade. Os resultados foram positivos no que diz respeito a participação, a prática no foro desenvolveu maior agilidade para discussão em grupos, bem como análise, elaboração de conclusões e síntese de ideias.

4 - No Equador o Cassette-foro foi iniciado em 1980 para intercomunicar grupos de camponeses (predominantemente indígenas) pertencentes às organizações da província do Cañar, no sul do país, para obter um fluxo de comunicação em prol da organização e capacitação dos camponeses de áreas distantes. E simultaneamente, outro programa acontecia entre professores e técnicos agrícolas que prestavam serviço em zonas distantes e que tinham os seguintes objetivos: fomentar um maior fluxo de informação desde a sede; possibilitar respostas críticas em forma de comentários; e iniciar comunicação com escritórios através do uso de cassetes. As experiências foram positivas e continuaram usando o C-F tanto para a intercomunicação entre os grupos de organização camponesa como para ao diálogo à distância e com os técnicos agrícolas.

5 - Em Bogotá, na Colômbia, o programa foi iniciado em 1983 para atender uma população urbana e suburbana, com grupos de mulheres das classes populares. $O$ objetivo era o de promover a intercomunicação entre grupos femininos de bairros e comunidades populares, residentes em torno de pequenas cooperativas de produção. 
O resultado mostra que os primeiros cassetes e foros suscitaram um forte impacto e já há resultado na tomada de decisão dos grupos de formar uma organização feminina popular que os potencialize.

6 - Na Bolívia, a necessidade e carências educativas são tão marcadas que fez-se eminente o início do Plano Nacional e Alfabetização e Educação Popular sob a coordenação do Serviço Nacional de Alfabetização e Educação Popular (SENALEP), criado pelo governo democrático, como uma entidade descentralizada do Ministério da Educação. E a finalidade do $\mathrm{C}-\mathrm{F}$ era a de fortalecer a organização nacional de camponeses. Se busca que através do intercâmbio e do diálogo, as comunidades rurais superem a reduzida visão localista e adquiram uma percepção mais global; que desenvolvam e reforcem seu sentido de pertencer a organização nacional que são seus núcleos.

7 - No Peru o projeto não atende especificamente à metodologia do C-F; são como variantes do projeto. Sem dúvida, parece pertinente mencionar porque tem muito em comum com ele: constitui canais de comunicação de duas vias e utilizam como meio o vídeo cassete. O programa peruano "Palavra de Mulher" deveria ser iniciado até 1984 pela Associação de Comunicadores Sociales "Calandia" de Lima. O programa tem como centro um espaço diário do rádio dirigido às mulheres das classes populares da capital peruana. A maior parte dessas mulheres eram camponesas que chegavam à Lima como consequência da intensa migração do campo para cidade.

8 - Na América Latina, o Escritório Regional de Educação para América Latina e Caribe (OREALC) pôs em prática outra aplicação do vídeo cassete para uma comunicação de duas vias, através do "Projeto Principal de Educação na América Latina e Caribe". Este projeto, aprovado por todos os governos da região estabeleceu o mútuo compromisso de realizar o "esforço renovado, intenso e sustentado para atender carências e necessidades educativas fundamentais" de nossos países latinos, dando a máxima prioridade a atenção dos grupos populacionais mais desfavorecidos, localizados nas zonas rurais e áreas suburbanas. Os estados membros têm encomendado para a Unesco a realização dos estudos necessários para execução do projeto.

Até esta altura, buscamos situar as teorias de Mario Kaplún e a sua disseminação nas práticas educomunicativas no âmbito da América Latina, num contexto de articulação entre as inovações tecnológicas nas comunicações e as estratégias educativas na constituição de ferramentas de ação emancipadora.

Neste sentido, a produção audiovisual de segmentos populares pode ser concebida como genuína prática da cidadania através do debate de temas de seu interesse social, fato que situa as ações educomunicativas como palco ao exercício da democracia nas relações sociais e mediante a participação comunitária. Assim é que a educomunicação é adotada como estratégia de organização de redes de comunicação e interação entre segmentos sociais.

Da mesma forma, as práticas educomunicativas constituem-se como espaço para o debate de direitos sociais e das minorias, fomentando a constituição de políticas públicas e ações a elas correlatas como estratégias de intercâmbio e diálogo entre comunidades e o fortalecimento da organização interna de segmentos sociais.

Em síntese, afirmamos que a Educomunicação demarca a sua relevância 
de grupos populacionais desfavorecidos na América Latina e no Caribe, constituindo-se como meio para o empoderamento dos sujeitos na construção de sua cidadania mediante a práxis cotidiana de seus pressupostos.

\section{Espaços e contextos de aplicabilidade da educomunicação}

O que se percebe é que na América Latina a prática da Educação através da Comunicação ocorre há muito tempo, não sendo o processo comunicativo, portanto, um fenômeno recente em âmbito continental. Nesta lógica, acreditamos que os setores populares, quer na América Latina, quer em outros espaços do globo terrestre, não querem continuar sendo meros ouvintes; eles querem falar e também querem ser escutados, querem ser interlocutores.

"No fundo das concepções de comunicação apresentadas o que há é uma questão básica que a humanidade enfrenta que é definir o que entendemos por comunicação, equivale a dizer em que classe de sociedade que queremos viver" (KAPLÚN, 2002, p. 57).

Desse modo, a educomunicação não representa uma simples metodologia operacional e pragmática, sem conexão com bases sociais, ideológicas e culturais. Pelo contrário, os processos educomunicativos surgem e se estruturam a partir da compreensão ideológica e libertadora da ação humana no mundo para transformálo.

A partir da conclusão de pesquisa sobre a relação Comunicação e Educação, coordenada pelo Prof. Ismar Soares junto ao Núcleo de Comunicação e Educação (NCE) da USP, passou-se a utilizar o termo Educomunicação para designar não apenas esforços em torno de uma "leitura crítica" das mensagens midiáticas, mas também as ações que compõem o complexo campo da interrelação Comunicação e Educação. Para Soares, o conceito de Educomunicação institui um conjunto de práticas voltadas para a formação de espaços educativos, mediados por processos tecnológicos da informação, e tem como objetivo ampliar formas de expressão dos membros das comunidades bem como a melhoria do nível comunicativo das ações educativas, tendo como meta o pleno desenvolvimento da cidadania.

Neste sentido, podemos dizer que nos anos 70 e 80 a Educomunicação surge como movimento em prol da cidadania. Segundo o Fórum Social Mundial, isto aconteceu com "a multiplicação de centros de documentação da cultura popular, em vários países da América Latina, que propunham uma comunicação alternativa como forma de resistência aos regimes autoritários do continente" (FSM, 2004). Soares (apud MENEZES, 2009) explica que estes movimentos sociais e culturais não foram impulsionados apenas pela educação e comunicação, mas por vários grupos de pessoas das diferentes áreas das ciências humanas que sentiam a necessidade de interferir na sociedade.

$\mathrm{Na}$ verdade, a Educomunicação surge como uma alternativa de comunicação na América Latina, um meio de resistência ao Regime Militar da 
época. Segundo Soares, várias ONGs surgiram durante os anos de 70 e $80 \mathrm{com}$ desejo de interferir de forma contundente nas várias camadas que compunham a sociedade da época. Estas não se utilizavam da imprensa apenas como alternativa para interferir na sociedade, mas também como forma de engajamento da reforma da sociedade em geral.

Podemos compreender o surgimento da Educomunicação como fruto de uma prática em prol da cidadania, e não somente das reflexões de filósofos e teóricos, restrita apenas ao campo do ensino formal.

Nesta perspectiva, Soares afirma que a Educomunicação não nasceu nas universidades, mas sim da prática e principalmente da militância - nasce de processos políticos e ideológicos. O objetivo do comunicador popular não era utilizar os meios, ao contrário, no período de 1960 a 1980 o objetivo era denunciálos. Na década de 1980 é que as orientações mudam, pois as estratégias políticas mudam, as pesquisas no campo acadêmico da comunicação apontam novos olhares e os próprios comunicadores populares repensam as suas práticas.

Logo após o relatório final do Projeto Perfil, em 1999, Ismar Soares apresentou academicamente o termo, que ele batizou de Educomunicação, sem criar uma nova área de conhecimento, mas tentando legitimar práticas dos comunicadores populares e sistematizar o movimento social em torno do que até então também era chamado de comunicação/educação ou inter-relação comunicação e educação. Soares, então, disse que existe um campo emergente de intervenção social cuja prática é realizada por alguém denominado "educomunicador". Este termo é mais amplo que o de "comunicador popular".

E segundo a descrição contida no Documento Técnico intitulado Programa de Educação Socioambiental, publicado pelo órgão Gestor da Política Nacional de Educação de Educação Ambiental (2005), Soares (2001) sistematizou a área de Educomunicação em cinco subáreas, a saber:

- expressão comunicativa através do uso dos recursos da informação e das artes;

- educação para a comunicação, configurada nos esforços sistemáticos de educadores no sentido de colaborar com os usuários dos meios massivos na formação do que Paulo Freire chamou de "consciência crítica", frente às mensagens editadas e veiculadas por poderosos sistemas de comunicação;

- mediação tecnológica nos espaços educativos, constituída pelos esforços no sentido de identificar a natureza da interatividade propiciada pelos novos instrumentos da comunicação e de democratizar 0 acesso às tecnologias, desmistificando-as e colocando-as a serviço de toda a sociedade;

- gestão da comunicação nos espaços educativos, caracterizada pela abordagem sistêmica das relações entre os recursos da comunicação e as atividades humanas, garantindo um planejamento e uma implementação organizada dos recursos da informação destinada a garantir a eficácia na construção dos ecossistemas comunicativos. Esta subárea, segundo o autor é a que garante a coordenação e eficiência às demais áreas e da visibilidade das ações Educomunicativas;

- reflexão epistemológica sobre o campo da Educomunicação, que inclui a pesquisa e a avaliação sistemática, destinadas a compreender a complexidade das relações entre Comunicação e Educação. 
$\mathrm{Na}$ apresentação dos elementos que a delineiam e ainda segundo Ismar Soares, o campo da Educomunicação é o resultado da inter-relação entre a Educação e a Comunicação e que na verdade abarca quatro áreas de intervenção: (1) a educação para os meios, que promove reflexão e forma indivíduos críticos, (2) o uso bem como a manipulação dos processos de produção midiática, (3) a utilização das tecnologias de informação e comunicação (TIC) no contexto de ensino aprendizagem e (4) a comunicação interpessoal no relacionamento entre grupos.

Dentro da perspectiva da Educomunicação proposta por Soares (2001), este campo implica na "implementação de políticas de comunicação educativa, tendo como objetivo geral o planejamento, a criação e desenvolvimento de ecossistemas educativos mediados por processos de comunicação e pelo uso das TICs." A partir do mesmo princípio a autora frisa que a Educação Ambiental é um campo para onde a Educação e a Comunicação, portanto, a Educomunicação, convergem naturalmente, por conta da sua esfera inter/transdisciplinar, e que ao mesmo tempo estimula a Educação Ambiental a ocupar espaços comunicativos com o objetivo de auxiliar na construção de uma "sociedade brasileira educada e educomunicando ambientalmente para a sustentabilidade".

\section{Considerações finais}

A partir desta tentativa de resgate, na forma de síntese, das experiências que levaram à atribuição de sentidos e significados ao conceito de educomunicação, é possível apontar, nas suas origens e a partir das experiências que nele se inspiraram, a educomunicação como espaços de escuta, interlocução e participação popular. Em outras palavras, situamos a práxis de educomunicação como exercício da criticidade, da argumentação, da ampliação das formas de expressão dos membros das comunidades, da formação de espaços educativos, e da melhoria do nível comunicativo das ações educativas.

$\mathrm{Na}$ consolidação da noção de educomunicação, constata-se a contribuição da academia, de segmentos sociais e culturais e elementos populares, evidenciando que esta proposta recebeu contribuições dos mais variados segmentos sociais e intelectuais no contexto latino-americano, não podendo ser considerada como monopólio de qualquer grupo social ou político.

É possível compreender que nas suas origens a educomunicação esteve atrelada a uma forma de resistência às ditaduras civis-militares da América Latina e meio ou ferramenta de organização política e luta pelo progresso social.

Vimos como se constituiu a progressiva interação entre os campos da educação e da comunicação, assim como os fatores que contribuíram ao surgimento da figura do educomunicador. Compreendemos, neste sentido, a educomunicação como ferramenta de educação ambiental através da articulação entre os processos educativos e as novas tecnologias da informação e comunicação.

Analisamos as subáreas do conhecimento humano que integram a educomunicação e seus componentes educativos, artísticos e tecnológicos. Assim 
como as aplicabilidades da educomunicação como educação para meios, produção midiática, relação de ensino e aprendizagem e enquanto relacionamento interno entre grupos sociais.

Por fim, compreendemos as ações educomunicativas como meio de praticar a comunicação ambiental e lutar em favor de uma sociedade sustentável a partir de estratégias como a organização de redes de interação social e de ecossistemas educativos.

Esses significados e sentidos podem contribuir, certamente, para uma compreensão da educomunicação socioambiental na sua dimensão de empoderamento, de autonomia, de possibilidade efetiva no favorecimento da transformação e da construção de um modelo civilizatório assentado na sustentabilidade.

\section{Referências}

CARACRISTI, M.F.A. As ideia de Mario Kaplún: fenômeno latino da comunicação educativa. Disponível em: <http://www2.metodista.br/unesco/PCLA/revista4/perfis\%204-2.htm\#Principais links> Acessado em 20 de agosto de 2014.

CITELLI, A. Comunicação e Educação. 1를. São Paulo: Senac, 2004.

FREIRE, M.T.M. ; CARAVALHO, D.W. Educomunicação: Construção Social e Desenvolvimento Humano - um relato de pesquisa. Seminário de Educação na Região Sul, 2012. Disponível em: $<$ http://www.ucs.br/etc/conferencias/index.php/anpedsul/9anpedsul/paper/viewFile/238 1/902> Acessado em 14/09/2012.

KAPLÚN, M. Producción de programas de rádio: El guión - la realización. CIESPAL; 1978.

KAPLÚN, M. A la educación por la comunicación. UNESCO: Chile, 1992.

KAPLÚN, M. Comunicación entre grupos: el método del cassette-foro. Otawa.

MELO, J.M. (Coord.). Mis primeros cincuenta anõs de aprendiz de comunicador. Miniautobiografia profesional. Mario Kaplún. Boletim Alaic. № 7 - 8 : São Paulo, 1992

SCHAUN, Â. Educomunicação: Reflexões e Princípios . 1ª ed., Rio de Janeiro: MAUAD Editora, 2002.

SOARES, I.O. La Comunicación/Educación como nuevo campo de conocimiento. In: VALDERRAMA, C.E. Comunicación-Educación: Coordinadas, Abordajes y Travesías. Universidad Central, Bogotá, 2000 p. 27-47.

SOARES, I.O. Uma Educomunição para a Cidadania, Disponível em $<$ http://www.usp.br/nce/aeducomunicacao/saibamais/textos/> acessado em $13 / 10 / 2001$. 